\title{
Low RAB6C expression is a predictor of tamoxifen benefit in estrogen receptor-positive/progesterone receptor-negative breast cancer
}

\author{
HELENA FOHLIN $^{1,2}$, TOVE BEKKHUS ${ }^{2}$, JOSEFINE SANDSTRÖM ${ }^{2}$, TOMMY FORNANDER ${ }^{3}$, \\ BO NORDENSKJÖLD ${ }^{2}$, JOHN CARSTENSEN ${ }^{4}$ and OLLE STÅL ${ }^{2}$
}

\author{
${ }^{1}$ Regional Cancer Center Southeast Sweden, SE-581 85 Linköping; ${ }^{2}$ Department of Clinical and Experimental Medicine and \\ Oncology, Linköping University, SE-581 83 Linköping; ${ }^{3}$ Department of Oncology, Karolinska University Hospital, \\ Karolinska Institute, SE-171 77 Stockholm; ${ }^{4}$ Division of Health and Society, Department of \\ Medical and Health Sciences, Linköping University, SE-581 83 Linköping, Sweden
}

Received April 9, 2019; Accepted January 30, 2020

DOI: $10.3892 / \mathrm{mco} .2020 .2014$

\begin{abstract}
Over the last few decades, improved and more individualized treatment has contributed to the increased survival rate of patients with breast cancer. However, certain patients may receive excessive treatment resulting in undesired side effects. In a previous study, it was demonstrated that systemically untreated patients with estrogen receptor (ER)-positive/progesterone receptor (PR)-negative tumors with high Ras-related protein Rab-6C (RAB6C) expression levels $\left(\mathrm{RAB}^{+} \mathrm{C}^{+}\right.$) had prolonged distant recurrence-free survival compared with that of patients exhibiting low RAB6C (RAB6C-)-expressing tumors. The aim of the present study was to investigate whether RAB6C predicts the effectiveness of tamoxifen treatment. The present study used a dataset comprising 486 female patients with $\mathrm{ER}^{+}$tumors from a randomized study conducted by the Stockholm Breast Cancer Study Group between November 1976 and August 1990. The patients were considered as low-risk if their tumor size was $\leq 30 \mathrm{~mm}$ and their lymph node status was negative. Patients were followed up until distant recurrence, mortality or when 25 years after randomization was achieved, whichever occurred first. For patients with $\mathrm{ER}^{+} / \mathrm{PR}^{-} / \mathrm{RAB} \mathrm{C}^{+}$tumors, prolonged distant recurrence-free survival could not be observed if the
\end{abstract}

Correspondence to: Dr Helena Fohlin, Regional Cancer Center Southeast Sweden, Brigadgatan 21, SE-581 85 Linköping, Sweden E-mail: helena.fohlin@regionostergotland.se

Abbreviations: CI, confidence interval; ER, estrogen receptor; HER2, human epidermal growth factor receptor 2; HR, hazard ratio; IHC, immunohistochemistry; NHG, Nottingham Histologic Grade; $\mathrm{PR}$, progesterone receptor; RAB6C, Ras-related protein Rab-6C; TAM, tamoxifen; TMA, tissue microarray

Key words: breast neoplasm, WTH3, RAB6A', endocrine therapy, hormone receptors patients were treated with tamoxifen [hazard ratio (HR), 1.82; 95\% confidence interval $(\mathrm{CI}), 0.69-4.79 ; \mathrm{P}=0.23]$, whereas patients with $\mathrm{ER}^{+} / \mathrm{PR}^{-} / \mathrm{RAB}^{-} \mathrm{C}^{-}$tumors had $75 \%$ reduced distant recurrence risk (HR, 0.25; 95\% CI, 0.09-0.70; $\mathrm{P}=0.008$ ). In the $\mathrm{ER}^{+} / \mathrm{PR}^{+}$subgroup, patients with $\mathrm{RAB}^{-} \mathrm{C}^{-}$and $\mathrm{RAB} 6 \mathrm{C}^{+}$ tumors benefited from tamoxifen treatment, though it was most evident in the $\mathrm{RAB}^{+} \mathrm{C}^{+}$group (HR, 0.27; 95\% CI, 0.13-0.58; $\mathrm{P}=0.001)$. The results of the present study indicated that, for patients with $\mathrm{ER}^{+} / \mathrm{PR}^{-}$tumors, those with low RAB6C expression benefited from tamoxifen treatment, whereas no benefit was observed in patients with high RAB6C levels.

\section{Introduction}

Breast cancer survival has increased continuously during the last decades, and the 5-year survival rate in Sweden is almost $90 \%(1,2)$. Improved and more individualized treatment has contributed to this progress. However, a few patients may be overtreated, possibly with undesired side effects. The majority of patients with estrogen receptor (ER)-positive tumors receive endocrine therapy. In a previous study, our group demonstrated that patients with $\mathrm{ER}^{+} /$progesterone receptor (PR)-positive tumors clearly did benefit from tamoxifen, while the long-term benefit was lower for those with $\mathrm{ER}^{+} / \mathrm{PR}^{-}$tumors (3). Nevertheless, $\mathrm{ER}^{+} / \mathrm{PR}^{-}$tumors are a heterogeneous group, and among them there may be subgroups of patients that do benefit from tamoxifen. Therefore, one subject for further study was the identification of such subgroups.

The $\mathrm{ER}^{+} / \mathrm{PR}^{-}$subgroup is considered to have a more aggressive progression compared with that of the $\mathrm{ER}^{+} / \mathrm{PR}^{+}$ subgroup, and according to the St. Gallen criteria, patients with $\mathrm{ER}^{+} / \mathrm{PR}^{-}$tumors are recommended chemotherapy as additional treatment, despite the fact that in this subgroup certain patients may have good prognosis without systemic treatment. Experimental studies have shown that the Ras-related protein RAB6C (RAB6C) inhibits proliferation, invasion and metastasis, suggesting that it acts as a tumor suppressor (4). RAB6C also interacts with p53, which is frequently mutated in breast cancer (5-7). In a concurrent study, it was revealed 
that systemically untreated patients with $\mathrm{ER}^{+} / \mathrm{PR}^{-}$tumors and high RAB6C expression (RAB6C ${ }^{+}$) had prolonged distant recurrence-free survival compared with that of patients with low RAB6C expression (RAB6C) (26). The aim of the present study was to investigate if RAB6C has a treatment predictive value for tamoxifen. For this purpose, data for 486 patients from a randomized clinical trial were used.

\section{Patients and methods}

Patients. Patients with operable invasive breast cancer were entered in a previous study of adjuvant tamoxifen therapy conducted by the Stockholm Breast Cancer Study Group (8). Postmenopausal women younger than 70 years of age were randomly administered tamoxifen postoperatively at a dose of $40 \mathrm{mg}$ per day compared with no adjuvant endocrine therapy. Between November 1976 and June 1990, 2,738 patients were recruited into the trial. Among them, 1,780 patients (65\%) with no lymph node metastases and a tumor diameter $\leq 30 \mathrm{~mm}$ (established by histological examination) were classified as 'low risk' and did not receive cytotoxic chemotherapy. In this group, 432 patients were treated with breast conserving surgery, including axillary dissection plus radiation to the breast (50 Gy/5 weeks). The remaining 1,348 patients had a modified radical mastectomy and no radiotherapy. Paraffin blocks from 912 low-risk patients were used for the construction of tissue microarrays (TMAs). Of these, 619 tumors were $\mathrm{ER}^{+}$, whereof 591 also had data on PR status (3). RAB6C expression could be evaluated for 486 cases among these tumors (Fig. 1).

Hormone receptor status, human epidermal growth factor receptor 2 (HER2) status, grade and RAB6C expression. Data on ER, PR and HER 2 was available from previous studies. The status of ER and PR was assessed retrospectively with immunohistochemistry (IHC) using the VENTANA ${ }^{\circledast}$ automated slide stainer (Ventana Medical Systems, Inc.). The primary monoclonal antibodies used were CONFIRM ${ }^{\mathrm{TM}}$ mouse anti-ER antibody (clone 6F11) and CONFIRM ${ }^{\mathrm{TM}}$ mouse anti-PR antibody (clone 16) (Ventana Medical Systems, Inc.). The cut-off level was set to $10 \%$ positively stained tumor cells (9). HER2 was analyzed with IHC as previously described (10). The Nottingham Histological Grade (NHG) was analyzed retrospectively by the same investigator for all tumor samples.

The protein expression of RAB6C was analyzed with IHC, and the staining pattern was evaluated independently by two investigators (JS and TB). The polyclonal rabbit antibody ab200396 (Abcam) was used. The intensity of RAB6C in the nucleus was analyzed and scored as $0,1,2$ or 3 . If the nuclei had an intensity $\geq 2$, the tumor was considered to have high expression of RAB6C $\left(\mathrm{RAB}^{+}\right)$. Otherwise, it was considered to have low RAB6C expression (RAB6C).

Ethics approval and patient consent to participate. The present study was performed in accordance with the Declaration of Helsinki. Ethical approval for the use of tumor material was approved by the local Ethical Committee at the Karolinska University Hospital (approval no. KI 97-451 with amendments 030201 and 171027). According to the approval, informed consent from the patients was not required.

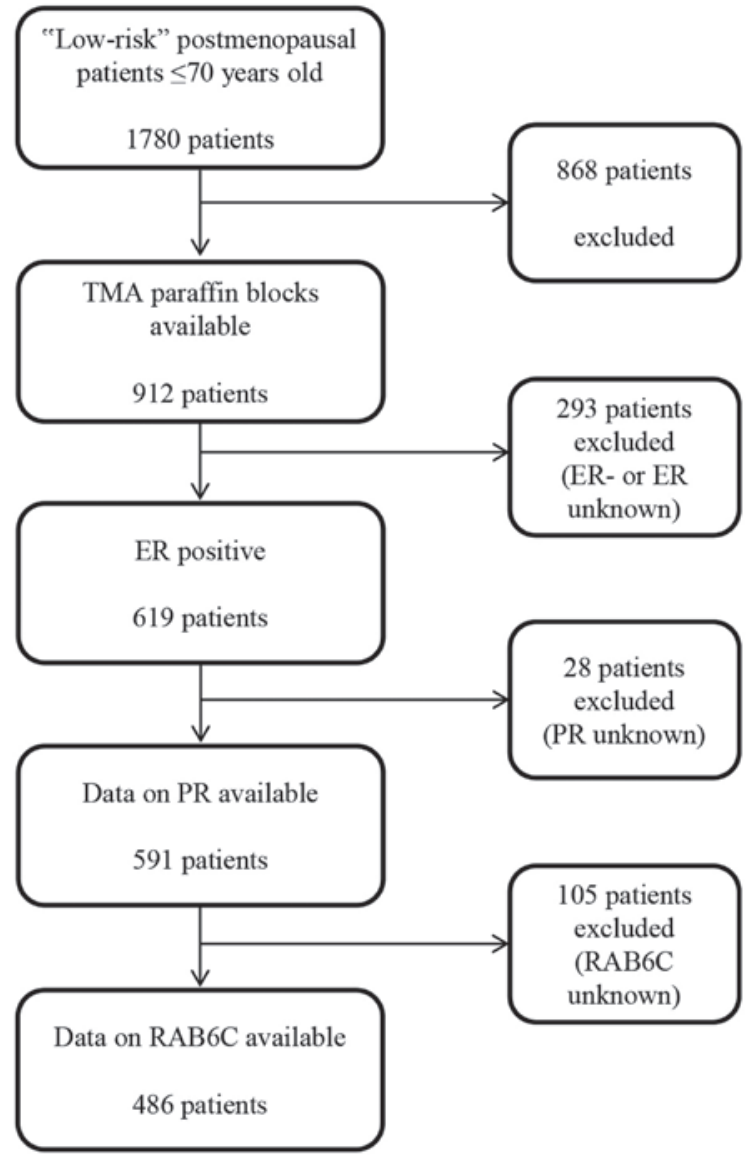

Figure 1. Consort diagram. TMA, tissue microarray; ER, estrogen receptor; $\mathrm{PR}$, progesterone receptor; Ras-related protein Rab-6C.

Statistical analysis. To compare the association between RAB6C and clinical characteristics, the Pearson's $\chi^{2}$ test was applied. Cumulative distant recurrence-free survival was estimated using the Kaplan-Meier method. The end-point was defined as the first distant recurrence from the patient's primary breast cancer as described by Rutqvist and Johansson (8). Three patients had succumbed to breast cancer but no date of distant recurrence was registered. For these patients, the date of death was used as an event of distant recurrence. The remaining patients were followed up until they had a distant recurrence or succumbed, or for 25 years after randomization, whichever occurred first. Patients were censored at the last follow-up or at mortality due to causes other than breast cancer.

The multivariable analyses with subgroups based on RAB6C status included age, tumor size, HER2, NHG, tamoxifen and the interaction term 'RAB6C $\mathrm{x}$ tamoxifen'. Hazard ratios (HRs) and 95\% confidence intervals (CIs) were estimated using the Cox's proportional hazards model. To test whether there is an interaction between RAB6C and tamoxifen, the Likelihood ratio $\chi^{2}$ test was applied. The statistical analyses were performed with Stata/SE 13.1 (StataCorp LP).

\section{Results}

Patients with $\mathrm{ER}^{+}$tumors did benefit from tamoxifen ( $\mathrm{HR}=0.47,95 \% \mathrm{CI}=0.31-0.71 ; \mathrm{P}<0.001)$, which was more evident in patients with $\mathrm{ER}^{+} / \mathrm{PR}^{+}$tumors $(\mathrm{HR}=0.39$, 
Table I. Univariable analysis of distant recurrence rates for tamoxifen-treated patients compared with the control group, stratified by hormonal receptor status.

\begin{tabular}{|c|c|c|c|c|c|}
\hline \multirow[b]{2}{*}{ Subgroup } & \multicolumn{2}{|c|}{$\begin{array}{c}\text { Number of } \\
\text { patients/events }\end{array}$} & \multirow{2}{*}{$\begin{array}{c}\text { HR }(95 \% \text { CI }) \\
\text { TAM+ vs. TAM- }\end{array}$} & \multirow[b]{2}{*}{ P-value } & \multirow[b]{2}{*}{$\mathrm{P}$ for interaction } \\
\hline & TAM+ & TAM- & & & \\
\hline $\mathrm{ER}^{+}$ & $259 / 35$ & $227 / 61$ & $0.47(0.3-0.71)$ & $<0.001$ & \\
\hline $\mathrm{ER}^{+} / \mathrm{PR}^{+}$ & $177 / 20$ & $143 / 39$ & $0.39(0.23-0.67)$ & 0.001 & 0.20 \\
\hline $\mathrm{ER}^{+} / \mathrm{PR}^{-}$ & $82 / 15$ & $84 / 22$ & $0.65(0.34-1.25)$ & 0.19 & \\
\hline $\mathrm{ER}^{+} / \mathrm{PR}^{+} / \mathrm{RAB} 6 \mathrm{C}^{+}$ & $111 / 10$ & $75 / 22$ & $0.27(0.13-0.58)$ & 0.001 & 0.14 \\
\hline $\mathrm{ER}^{+} / \mathrm{PR}^{+} / \mathrm{RAB}^{-} \mathrm{C}^{-}$ & $66 / 10$ & $68 / 17$ & $0.63(0.29-1.37)$ & 0.24 & \\
\hline $\mathrm{ER}^{+} / \mathrm{PR}^{-} / \mathrm{RAB} \mathrm{C}^{+}$ & $37 / 10$ & $41 / 7$ & $1.82(0.69-4.79)$ & 0.23 & 0.004 \\
\hline $\mathrm{ER}^{+} / \mathrm{PR}^{-} / \mathrm{RAB}^{-} \mathrm{C}^{-}$ & $45 / 5$ & $43 / 15$ & $0.25(0.09-0.70)$ & 0.008 & \\
\hline
\end{tabular}

The control group is the referent (hazard ratio, 1) in each subgroup analysis. ER, estrogen receptor; PR, progesterone receptor; RAB6C, Ras-Related protein Rab-6C.

A

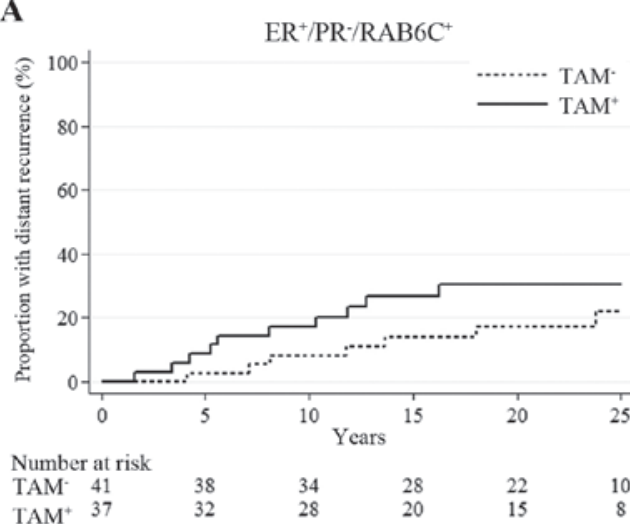

C

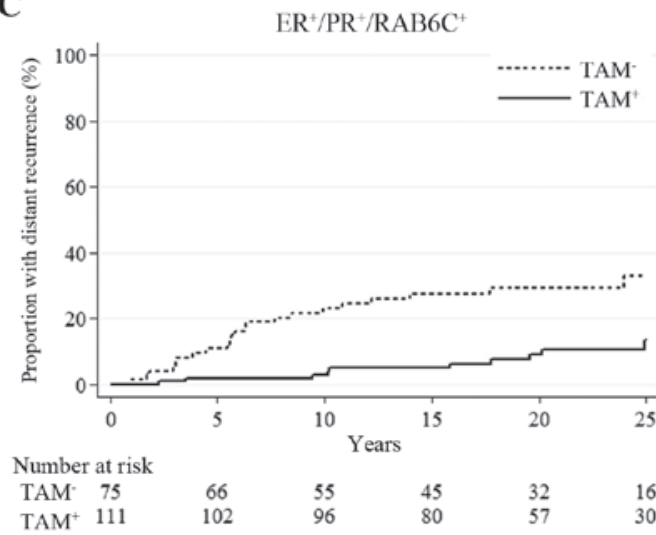

B

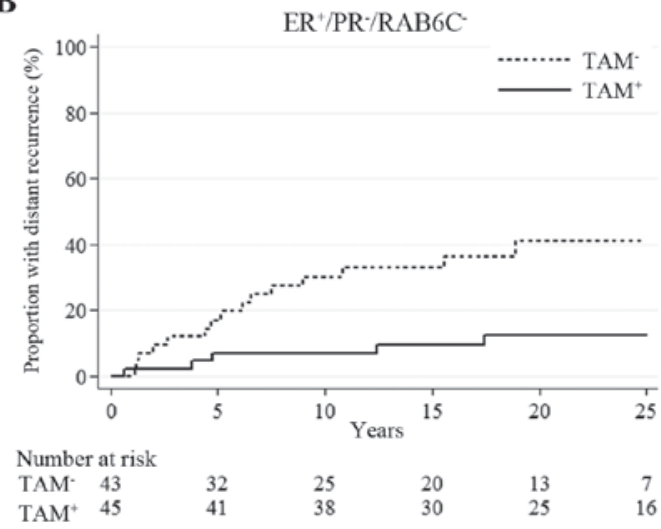

D

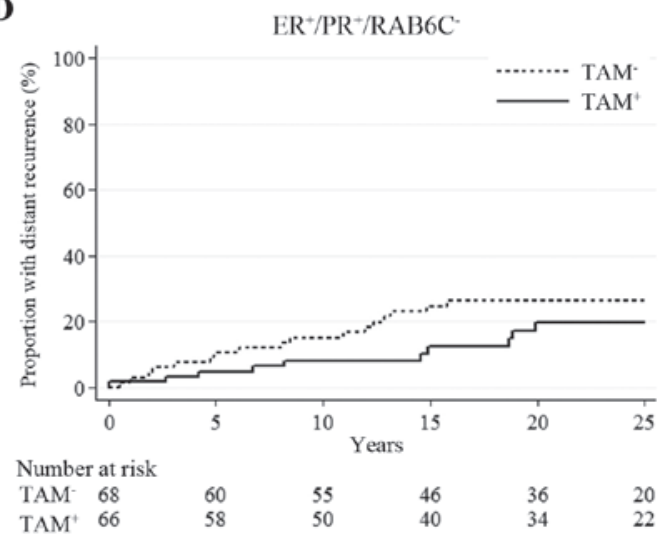

Figure 2. Cumulative distant recurrence risk in relation to tamoxifen treatment in patients with (A) $\mathrm{ER}^{+} / \mathrm{PR}^{-} / \mathrm{RAB} 6 \mathrm{C}^{+}(\mathrm{HR}, 1.82 ; 95 \% \mathrm{CI}, 0.69-4.79 ; \mathrm{P}=0.23)$, (B) $\mathrm{ER}^{+} / \mathrm{PR}^{-} / \mathrm{RAB} 6 \mathrm{C}^{-}(\mathrm{HR}, 0.25 ; 95 \% \mathrm{CI}, 0.09-0.70 ; \mathrm{P}=0.008)$, (C) $\mathrm{ER}^{+} / \mathrm{PR}^{+} / \mathrm{RAB}^{+} \mathrm{C}^{+}(\mathrm{HR}, 0.27 ; 95 \% \mathrm{CI}, 0.13-0.58 ; \mathrm{P}=0.001)$ and $(\mathrm{D}) \mathrm{ER}^{+} / \mathrm{PR}^{+} / \mathrm{RAB}^{-}$(HR, 0.63; 95\% CI, 0.29-1.37; P=0.24) tumors. CI, confidence interval; ER, estrogen receptor; HR, hazard ratio; PR, progesterone receptor; RAB6C, Ras-related protein Rab-6C; TAM, tamoxifen.

95\% $\mathrm{CI}=0.23-0.67 ; \mathrm{P}=0.001)$ than in those with $\mathrm{ER}^{+} / \mathrm{PR}^{-}$ tumors $(\mathrm{HR}=0.65,95 \% \mathrm{CI}=0.34-1.25 ; \mathrm{P}=0.19)$. However, dividing the $\mathrm{ER}^{+} / \mathrm{PR}^{-}$tumors by $\mathrm{RAB} 6 \mathrm{C}$ status showed that, for those with low RAB6C expression levels, the tamoxifen effect on disease $(\mathrm{HR}=0.25,95 \% \mathrm{CI}=0.09-0.70 ; \mathrm{P}=0.008)$ was comparable to that in patients with $\mathrm{ER}^{+} / \mathrm{PR}^{+}$tumors (Fig. 2).
For patients with $\mathrm{ER}^{+} / \mathrm{PR}^{-} / \mathrm{RAB} 6 \mathrm{C}^{+}$tumors, prolonged distant recurrence-free survival was not observed if they were treated with tamoxifen $(\mathrm{HR}=1.82,95 \% \mathrm{CI}=0.69-4.79 ; \mathrm{P}=0.23)$. The different effect of the treatment between the $\mathrm{RAB} \mathrm{C}^{+}$and RAB6C- groups was indicated by a statistically significant interaction $\left(\mathrm{P}=0.004\right.$; Table I). In the $\mathrm{ER}^{+} / \mathrm{PR}^{+}$subgroup, 
Table II. Multivariable ${ }^{\mathrm{a}}$ analysis of distant recurrence rates for tamoxifen-treated patients compared with the control group, stratified by hormonal receptor status.

\begin{tabular}{|c|c|c|c|c|c|c|}
\hline \multirow[b]{2}{*}{ Subgroup } & \multicolumn{2}{|c|}{$\begin{array}{c}\text { Number of } \\
\text { patients/events }\end{array}$} & \multirow{2}{*}{$\begin{array}{c}\text { HR }(95 \% \text { CI }) \\
\text { TAM+ vs. TAM- }\end{array}$} & \multirow[b]{2}{*}{ P-value } & \multicolumn{2}{|c|}{$\begin{array}{c}\text { LR interaction } \\
\text { term RAB6C x TAM }\end{array}$} \\
\hline & TAM + & TAM- & & & $\chi^{2}$ value & P-value \\
\hline $\mathrm{ER}^{+} / \mathrm{PR}^{+} / \mathrm{RAB} \mathrm{C}^{+}$ & $88 / 7$ & $69 / 20$ & $0.17(0.07-0.42)$ & $<0.001$ & 4.63 & 0.03 \\
\hline $\mathrm{ER}^{+} / \mathrm{PR}^{+} / \mathrm{RAB} \mathrm{C}^{-}$ & $58 / 10$ & $55 / 15$ & $0.61(0.27-1.37)$ & 0.23 & & \\
\hline $\mathrm{ER}^{+} / \mathrm{PR} / \mathrm{RAB} 6 \mathrm{C}^{+}$ & $32 / 7$ & $32 / 4$ & $2.18(0.61-7.78)$ & 0.23 & 10.17 & 0.001 \\
\hline $\mathrm{ER}^{+} / \mathrm{PR}^{-} / \mathrm{RAB} \mathrm{C}^{-}$ & $40 / 4$ & $40 / 15$ & $0.19(0.06-0.57)$ & 0.003 & & \\
\hline
\end{tabular}

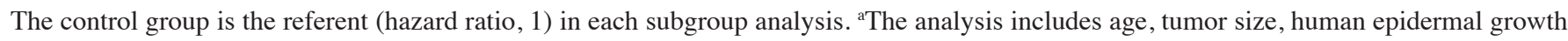
factor receptor 2 status, Nottingham Histologic Grade, RAB6C, TAM and the interaction term 'RAB6C x TAM'. RAB6C, Ras-related protein Rab-6C; TAM, tamoxifen; LR, Likelihood ratio; ER, estrogen receptor; PR, progesterone receptor; HR, hazard ratio; CI, confidence interval.

RAB6C expression did not have a significant influence on benefit from tamoxifen. Both patients with RAB6C- tumors $(\mathrm{HR}=0.63,95 \% \mathrm{CI}=0.29-1.37 ; \mathrm{P}=0.24)$ and $\mathrm{RAB}^{+} \mathrm{C}^{+}$tumors $(\mathrm{HR}=0.27,95 \% \mathrm{CI}=0.13-0.58 ; \mathrm{P}=0.001)$ did benefit from tamoxifen, although it was statistically significant only among those with $\mathrm{RAB}^{+} \mathrm{C}^{+}$tumors. Of note, the tamoxifen-treated patients with $\mathrm{ER}^{+} / \mathrm{PR}^{+} / \mathrm{RAB} \mathrm{C}^{+}$or $\mathrm{ER}^{+} / \mathrm{PR}^{-} / \mathrm{RAB}^{-} \mathrm{C}^{-}$tumors had excellent distant recurrence-free survival, with a $25-y e a r$ cumulative proportion of $87 \%(95 \% \mathrm{CI}=75-93 \%)$ and $88 \%$ (95\% CI $=72-95 \%)$, respectively. Together, these patients represent $60 \%$ of all patients with $\mathrm{ER}^{+}$disease treated with tamoxifen.

Established clinical factors were similarly distributed in the tamoxifen-treated and control groups (Table SI). In multivariable analyses divided by PR status and adjusting for age, tumor size, HER2 status and NHG, the results were similar to those obtained in univariable analyses, indicating that the treatment effect of tamoxifen on disease depending on the RAB6C expression was independent of these factors (Tables I and II). In summary, the analyses revealed that it was favorable to treat patients with $\mathrm{ER}^{+} / \mathrm{PR}^{+}$tumors regardless of RAB6C expression status. In contrast to high RAB6C expression, low RAB6C expression predicted benefit from tamoxifen for patients with $\mathrm{ER}^{+} / \mathrm{PR}^{-}$tumors.

\section{Discussion}

The hormone receptors ER and PR are important markers for breast cancer treatment. While tumors that are positive for both receptors are associated with prolonged survival when patients are treated with endocrine therapy, $\mathrm{ER}^{+} / \mathrm{PR}^{-}$tumors are considered to have a more aggressive phenotype (11). Patients with this tumor subtype are mostly treated with both endocrine therapy and chemotherapy, but there are probably subgroups of patients with these tumors who have high survival rates with more limited treatment. In a concurrent study, the results indicated that RAB6C may identify such patients (26). The present study further investigated the role of RAB6C in a retrospective study based on clinical data with patients randomized to be treated with endocrine therapy (tamoxifen) or included in the control group. Among patients with $\mathrm{ER}^{+} / \mathrm{PR}^{-}$tumors, tamoxifen treatment showed different effects depending on RAB6C expression, and patients with low RAB6C expression did benefit from tamoxifen. For patients with $\mathrm{ER}^{+} / \mathrm{PR}^{+}$tumors, there was no statistically significant difference in treatment effect on $\mathrm{RAB}^{+} \mathrm{C}^{+}$or $\mathrm{RAB}^{-} \mathrm{C}^{-}$disease.

The relevance of $\mathrm{PR}$ for tamoxifen benefit has been discussed in various studies $(3,12-16)$. Several of them concluded that patients with $\mathrm{ER}^{+} / \mathrm{PR}^{+}$tumors did benefit from tamoxifen treatment, whilst patients with $\mathrm{ER}^{+} / \mathrm{PR}^{-}$tumors benefit less. There is a need to identify patients with $\mathrm{ER}^{+} / \mathrm{PR}^{-}$tumors that do benefit from tamoxifen. The results of the present study confirmed that patients with $\mathrm{ER}^{+} / \mathrm{PR}^{+}$tumors benefit from tamoxifen, whereas for those with $\mathrm{ER}^{+} / \mathrm{PR}^{-}$tumors, the effect depends on $\mathrm{RAB} 6 \mathrm{C}$ status. Potential physical interactions between RAB6C and the hormone receptors need to be evaluated in further studies. A number of samples from the original cohort was missing on the TMAs. However, in a previous study, the results showed no bias in the missing cases with respect to tumor size, ER status or tamoxifen treatment (17).

The knowledge of RAB6C is limited, although it is known to be a member of the RAB6 family and consists of a single exon. RAB6C shares $97 \%$ identity with the $R A B 6 A^{\prime}$ transcript, leading to the hypothesis that $R A B 6 C$ was generated by retrotransposition of a fully processed $R A B 6 A^{\prime}$ mRNA, and encodes a functional protein different from that coded by RAB6A' (18). RAB6C is most highly expressed in brain, prostate, testis, breast and cervical tissues, and appears to participate not only in breast cancer $(18,19)$. In cervical cancer, $R A B 6 C$ promoter methylation analysis has been shown to have high sensitivity and specificity in distinguishing between malignant, premalignant and normal tissue, while in squamous cell carcinoma of the tongue, patients with low $R A B 6 C$ expression levels had poorer survival times than those with high $R A B 6 C$ expression $(20,21)$. This is also in line with our study on the prognostic value of RAB6C in breast cancer (26). Furthermore, the long non-protein coding RAB6C antisense RNA 1 (RAB6C-AS1) is frequently overexpressed in gastric and breast cancer, and often deleted in prostate and pancreatic cancer and in brain tumors. Its gene is located in the same chromosomal region as RAB6C and both genes are often co-expressed (22). Results from previous experimental 
studies on breast cancer cell lines indicated that RAB6C has properties as a tumor suppressor with the capability to inhibit proliferation, invasion and metastasis, and promote apoptosis $(4,18)$. It has also been suggested that $R A B 6 C$ may increase sensitivity to various drugs (23-25). The present study investigated the predictive value of RAB6C in relation to tamoxifen therapy with data from a randomized clinical study. For untreated control patients with $\mathrm{ER}^{+} / \mathrm{PR}^{-}$tumors, those with tumors expressing low RAB6C levels had a higher recurrence rate than untreated patients with tumors expressing high RAB6C levels. A higher number of events in the control group with low RAB6C expression increased the probability of observing differences between treated and untreated patients. Therefore, the data showing a difference in benefit from tamoxifen therapy in patients with $\mathrm{ER}^{+} / \mathrm{PR}^{-}$tumors depending on the RAB6C expression, should be interpreted with care. Additional data are needed before clinical practice may be influenced. For patients with $\mathrm{ER}^{+} / \mathrm{PR}^{-}$tumors, more tailored therapy is required, and the results of the present study may contribute to the identification of clinically relevant subgroups.

\section{Acknowledgements}

The authors would like to thank Mrs. Ulla Johansson (Regional Cancer Center of Stockholm Gotland, Stockholm, Sweden) for updating the database and Mrs Birgitta Holmlund (Department of Oncology, Linköping University Hospital, Linköping, Sweden) for technical assistance. The authors would also like to thank Dr Dennis Sgroi (Department of Pathology, Massachusetts General Hospital, Boston, MA USA) for providing information on tumor grading.

\section{Funding}

The present study was supported by grants from the Swedish Cancer Society (grant no. 17-0479), The Cancer Research Foundation of Radiumhemmet, Cancer Society in Stockholm and King Gustav V Jubilee Clinical Research Foundation (grant no. 181093), Onkologiska klinikerna i Linköpings forskningsfond (grant no. 2016-06-21), ALF grants Region Östergötland (grant no. LIO-795201) and County Council of Östergötland (grant no. LIO-625491). The funders did not have any role in the study design, collection, analysis, interpretation of data, writing of the manuscript or the decision to submit the manuscript for publication.

\section{Availability of data and materials}

The datasets used and/or analyzed during the present study is available from the corresponding author on reasonable request.

\section{Authors' contributions}

HF, JC and OS conceived the study and participated in the study design and coordination. TF and BN provided the study materials, collected clinical follow-up data and hormone receptor data from patients and performed clinical interpretations. TB and JS performed the laboratory experiments and scored RAB6C. HF performed the statistical analysis and drafted the manuscript. HF, JC, OS, TB, JS, BN and TF interpreted the results, provided critical revision. All authors read and approved the final manuscript.

\section{Ethics approval and patient consent to participate}

The present study was performed in accordance with the Declaration of Helsinki. Ethical approval for the use of tumor material was approved by the local Ethical Committee at the Karolinska University Hospital (Stockholm, Sweden) (approval no. KI 97-451 with amendments 030201 and 171027). According to the approval, informed consent from the patients was not required.

\section{Patient consent for publication}

Not applicable.

\section{Competing interests}

The authors declare that they have no competing interests.

\section{References}

1. Sant M, Chirlaque Lopez MD, Agresti R, Sánchez Pérez MJ, Holleczek B, Bielska-Lasota M, Dimitrova N, Innos K, Katalinic A, Langseth H, et al: Survival of women with cancers of breast and genital organs in Europe 1999-2007: Results of the EUROCARE-5 study. Eur J Cancer 51: 2191-2205, 2015.

2. Fredholm H, Magnusson K, Lindström LS, Garmo H, Fält SE, Lindman H, Bergh J, Holmberg L, Pontén F, Frisell J and Fredriksson I: Long-term outcome in young women with breast cancer: A population-based study. Breast Cancer Res Treat 160: 131-143, 2016.

3. Nordenskjöld A, Fohlin H, Fornander T, Löfdahl B, Skoog L and Stål O: Progesterone receptor positivity is a predictor of long-term benefit from adjuvant tamoxifen treatment of estrogen receptor positive breast cancer. Breast Cancer Res Treat 160: 313-322, 2016.

4. Gan L, Zuo G, Wang T, Min J, Wang Y, Wang Y and Lv G: Expression of WTH3 in breast cancer tissue and the effects on the biological behavior of breast cancer cells. Exp Ther Med 10: 154-158, 2015

5. Cancer Genome Atlas Network: Comprehensive molecular portraits of human breast tumours. Nature 490: 61-70, 2012.

6. Haverty PM, Fridlyand J, Li L, Getz G, Beroukhim R, Lohr S, Wu TD, Cavet G, Zhang Z and Chant J: High-resolution genomic and expression analyses of copy number alterations in breast tumors. Genes Chromosomes Cancer 47: 530-542, 2008.

7. Tian K, Wang Y and Xu H: WTH3 is a direct target of the p53 protein. Br J Cancer 96: 1579-1586, 2007.

8. Rutqvist LE and Johansson H; Stockholm Breast Cancer Study Group: Long-term follow-up of the randomized Stockholm trial on adjuvant tamoxifen among postmenopausal patients with early stage breast cancer. Acta Oncol 46: 133-145, 2007.

9. Khoshnoud MR, Löfdahl B, Fohlin H, Fornander T, Stål O, Skoog L, Bergh J and Nordenskjöld B: Immunohistochemistry compared to cytosol assays for determination of estrogen receptor and prediction of the long-term effect of adjuvant tamoxifen. Breast Cancer Res Treat 126: 421-430, 2011.

10. Jerevall PL, Jansson A, Fornander T, Skoog L, Nordenskjöld B and Stål O: Predictive relevance of HOXB13 protein expression for tamoxifen benefit in breast cancer. Breast Cancer Res 12: R53, 2010.

11. Thakkar JP and Mehta DG: A review of an unfavorable subset of breast cancer: Estrogen receptor positive progesterone receptor negative. Oncologist 16: 276-285, 2011.

12. Dowsett M, Houghton J, Iden C, Salter J, Farndon J, A'Hern R, Sainsbury R and Baum M: Benefit from adjuvant tamoxifen therapy in primary breast cancer patients according oestrogen receptor, progesterone receptor, EGF receptor and HER2 status. Ann Oncol 17: 818-826, 2006. 
13. Bartlett JM, Brookes CL, Robson T, van de Velde CJ, Billingham LJ, Campbell FM, Grant M, Hasenburg A, Hille ET, Kay $\mathrm{C}$, et al: Estrogen receptor and progesterone receptor as predictive biomarkers of response to endocrine therapy: A prospectively powered pathology study in the Tamoxifen and Exemestane adjuvant multinational trial. J Clin Oncol 29: 1531-1538, 2011.

14. Early Breast Cancer Trialists' Collaborative Group (EBCTCG), Davies C, Godwin J, Gray R, Clarke M, Cutter D, Darby S, McGale P, Pan HC, Taylor C, et al: Relevance of breast cancer hormone receptors and other factors to the efficacy of adjuvant tamoxifen: Patient-level meta-analysis of randomised trials. Lancet 378: 771-784, 2011.

15. Bardou VJ, Arpino G, Elledge RM, Osborne CK and Clark GM: Progesterone receptor status significantly improves outcome prediction over estrogen receptor status alone for adjuvant endocrine therapy in two large breast cancer databases. J Clin Oncol 21: 1973-1979, 2003.

16. Viale G, Regan MM, Maiorano E, Mastropasqua MG, Dell'Orto P, Rasmussen BB, Raffoul J, Neven P, Orosz Z, Braye S, et al: Prognostic and predictive value of centrally reviewed expression of estrogen and progesterone receptors in a randomized trial comparing letrozole and tamoxifen adjuvant therapy for postmenopausal early breast cancer: BIG 1-98. J Clin Oncol 25: 3846-3852, 2007.

17. Bostner J, Skoog L, Fornander T, Nordenskjöld B and Stål O: Estrogen receptor-alpha phosphorylation at serine 305, nuclear p21-activated kinase 1 expression, and response to tamoxifen in postmenopausal breast cancer. Clin Cancer Res 16: 1624-1633, 2010.

18. Young J, Ménétrey J and Goud B: RAB6C is a retrogene that encodes a centrosomal protein involved in cell cycle progression. J Mol Biol 397: 69-88, 2010.

19. Uhlén M, Fagerberg L, Hallström BM, Lindskog C, Oksvold P, Mardinoglu A, Sivertsson A, Kampf C, Sjöstedt E, Asplund A, et al: Proteomics. Tissue-based map of the human proteome. Science 347: 1260419, 2015.
20. Bhat S, Kabekkodu SP, Varghese VK, Chakrabarty S, Mallya SP, Rotti H, Pandey D, Kushtagi P and Satyamoorthy K: Aberrant gene-specific DNA methylation signature analysis in cervical cancer. Tumour Biol 39: 1010428317694573, 2017.

21. Bhat S, Kabekkodu SP, Jayaprakash C, Radhakrishnan R, Ray S and Satyamoorthy K: Gene promoter-associated $\mathrm{CpG}$ island hypermethylation in squamous cell carcinoma of the tongue. Virchows Arch 470: 445-454, 2017.

22. Salavaty A, Motlagh FM, Barabadi M, Cheshomi $\mathrm{H}$, Esmatabadi MJD, Shahmoradi M and Soleimanpour-Lichaei HR: Potential role of RAB6C-AS1 long noncoding RNA in different cancers. J Cell Physiol 234: 891-903, 2018.

23. Tian K, Wang Y, Huang Y, Sun B, Li Y and Xu H: Methylation of WTH3, a possible drug resistant gene, inhibits p53 regulated expression. BMC Cancer 8: 327, 2008.

24. Shan J, Mason JM, Yuan L, Barcia M, Porti D, Calabro A, Budman D, Vinciguerra V and Xu H: Rab6c, a new member of the rab gene family, is involved in drug resistance in MCF7/AdrR cells. Gene 257: 67-75, 2000.

25. Shan J, Yuan L, Budman DR and Xu HP: WTH3, a new member of the Rab6 gene family, and multidrug resistance. Biochim Biophys Acta 1589: 112-123, 2002.

26. Fohlin H, Bekkhus T, Sandström J, Fornander T, Nordenskjöld B, Carstensen J and Stål O: RAB6C is an independent prognostic factor of estrogen receptor-positive/progesterone receptornegative breast cancer. Oncol Lett 19: 52-60, 2020.

This work is licensed under a Creative Commons Attribution-NonCommercial-NoDerivatives 4.0 International (CC BY-NC-ND 4.0) License. 